\title{
AI/ML Applications for Aerospace and Defense
}

\author{
Kishore K. Reddy ${ }^{1}$, Amit Surana ${ }^{1}$, Paul Kodzwa ${ }^{1(凶)}$, Shane Zable ${ }^{2}$, \\ Richard LaRowe ${ }^{3}$, Eric Brewer ${ }^{4}$, and Steven Burd ${ }^{5}$ \\ 1 Raytheon Technologies Research Center, East Hartford, CT 06108, USA \\ \{kishore.reddy, paul.kodzwa\}@rtx.com \\ 2 Raytheon Intelligence and Space, Arlington, VA 22209, USA \\ 3 Raytheon Missile and Defense, Tucson, AZ 85756, USA \\ ${ }^{4}$ Collins Aerospace, Cedar Rapids, IA 52498, USA \\ 5 Pratt and Whitney, East Hartford, CT 06108, USA
}

\begin{abstract}
The vast majority of leading executives with aerospace and defense industries expect artificial intelligence (AI) technologies to influence every part of their operations over the next decade. Security leaders have recognized that the human cognitive band-width is emerging as the most severe constraint for data utilization. For this reason, governments need big data, AI and machine learning (ML) to give its analysts the edge in real-time response. Similarly, commercial aerospace is actively seeking AI "killer apps" to revolutionize operations through reducing fuel consumption, accelerating pilot training, innovative product designs and better customer service. For ex-ample, as a leading aerospace and defense corporation, Raytheon Technologies (RTX) is actively exploring the transformative capabilities of AI and ML. This panel discussion will present examples and experiences across all RTX business units.
\end{abstract}

Keywords: Artificial intelligence $\cdot$ Machine learning $\cdot$ Revolutionizing aerospace and defense 